
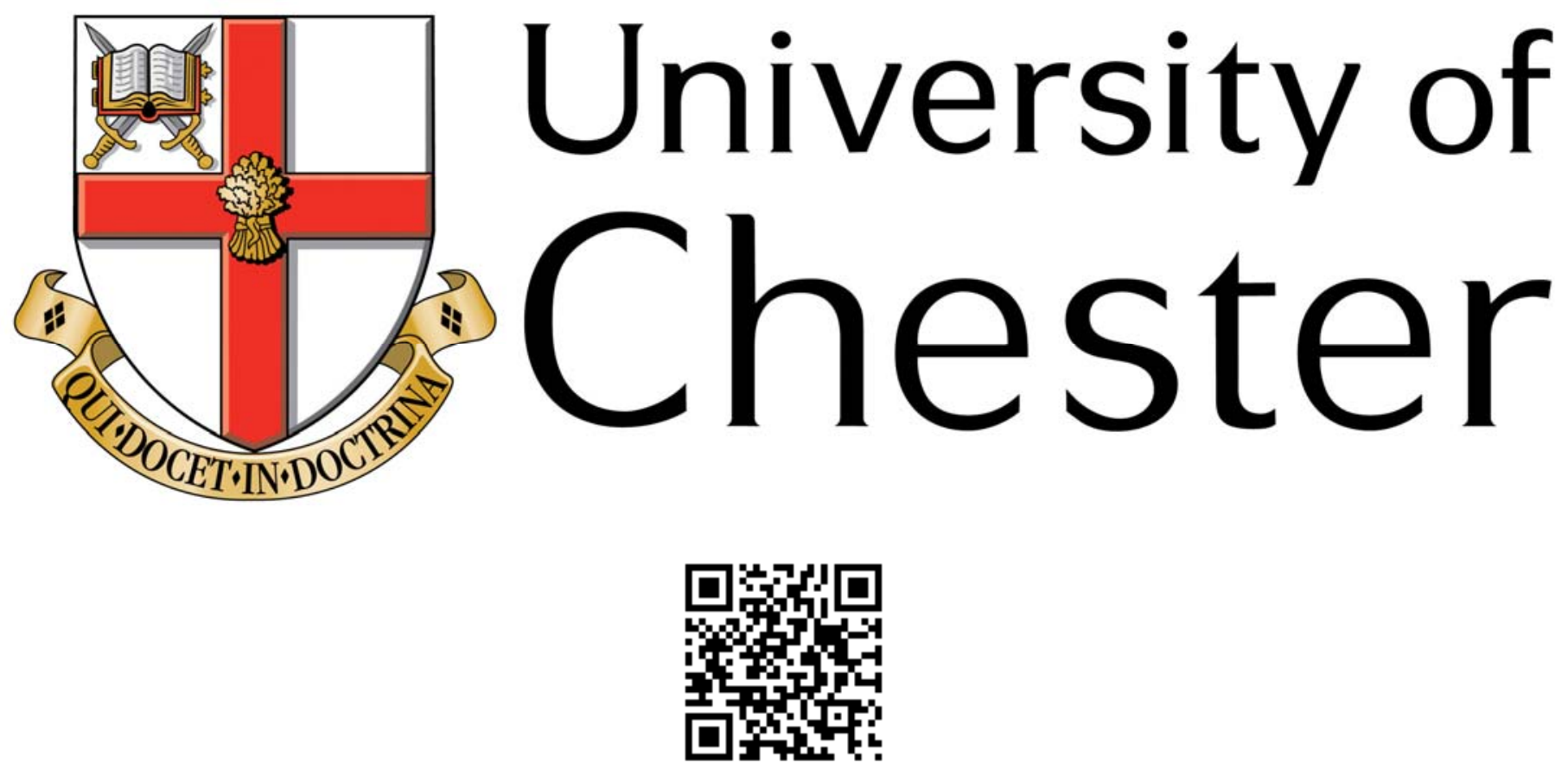

This work has been submitted to ChesterRep - the University of Chester's online research repository

\title{
http://chesterrep.openrepository.com
}

Author(s): Ruth L Healey

Title: Asylum-seekers and refugees: A structuration theory analysis of their experiences in the UK 2006

Date: 2006

Originally published in: Population, Space and Place

Example citation: Healey, R. L. (2006). Asylum-seekers and refugees: A structuration theory analysis of their experiences in the UK 2006. Population, Space and Place, 12(4), 257-271

Version of item: Author's accepted version 


\title{
Asylum seekers and refugees: a structuration theory analysis of their experiences in the UK
}

\author{
Ruth L Healey \\ University of Sheffield
}

Ruth Healey is a research student at the University of Sheffield. Her research interests are in migration geography with specific reference to the adjustment behaviour of asylum seekers and refugees, particularly in regards to the utilisation of their skills.

University of Sheffield

Department of Geography

Winter Street

Sheffield

S10 2NT

07813566521

R.Healey@sheffield.ac.uk 


\title{
Asylum seekers and refugees: a structuration theory analysis of their experiences in the UK
}

\begin{abstract}
Much of the literature on asylum seekers and refugees tends to be atheoretical. This article uses ideas from Giddens' structuration theory as a conceptual framework to analyse the voices of a group of asylum seekers and refugees. The empirical database consists of semistructured interviews with 18 asylum seekers and refugees living in the UK from a wide range of countries, including Ethiopia, Kenya, Poland, Somalia, and the Yemen. The study shows that the experiences of asylum seekers and refugees are impacted by both structural and individual agency factors. The former, it is argued, consist of public and political reaction towards the increase in the number of asylum applications, while the latter include asylum seeker and refugee experiences of specific places and people which can create social networks. Structural factors had the greatest impact upon the integration of the participants into the host society. The nature of the experiences of asylum seekers and refugees can influence the way they feel about their position in the host society. For example, negative experiences of the UK can reduce their sense of security in the society whereas positive experiences can increase their feelings of comfort. Structuration theory conceptualises how asylum seekers and refugees utilise coping strategies to raise their comfort level in the host country.
\end{abstract}

Keywords: population geography, asylum seekers, refugees, structuration theory, experiences, coping strategies. 


\section{THEORISING THE UNTHEORISED}

This article contributes to earlier discussions about the role of theory within population geography. As Silvey (2004: 303) argues 'for over a decade, population geographers have been calling for scholars within the subfield to engage more deeply with developments in social theory'. In the 1990s a re-emphasis was given to theoretical development within the field of population geography; for example, Halfacree and Boyle's (1993) study focused on the biographical approach, and White and Jackson (1995) called for a 're-theorisation of population geography’. More recently Graham (2000) suggested returning to demographic transition theory and other 'layers of theory' that underpin population research. Findlay (2004: 187) sums up how 'the challenge facing population geographers at the start of the 1990s was to engage with a wider theorisation of their work... the advances that have been achieved in these realms have been quite small, but very valuable'. Theory is a way of strengthening the subfield and deepening understandings of population in an ever changing world (Silvey, 2004). Theoretical approaches allow a deeper conceptualisation of empirical data.

Most previous studies of asylum seekers and refugees have been atheoretical (with a few exceptions, such as Richmond, 1993). For example, Wahlbeck (2002: 221) argues that 'there is an abundance of literature on refugees, but only a fraction makes an effort to discuss conceptual or theoretical questions'. A few articles have looked at aspects of theory, for example Richmond (1993) directly uses structuration theory to examine the movements of refugees, and ideas relating to the same theory are used indirectly by Al-Ali et al (2001a) to discuss the 'capabilities' of refugees to partake in transnational connections - in essence the 'agency' of the individuals within a structuration argument. This paper seeks to contribute to the theorisation of refugee studies by analysing the voices of asylum seekers and refugees and their experiences within the conceptual framework of structuration theory.

The main focus of this paper is on the two sides of the same 'coin': agency and structure. Structural forces are the underlying structures of society which produce or shape human actions; whereas human agency is defined as 'the capabilities of human beings' (Gregory, 2000a: 350) and is an indication of the level of self determination possessed by 
an individual. Goss and Lindquist (1995) argue that structures both enable and constrain the actions of human agents as they are drawn upon in their everyday lives. This study seeks to illustrate the wide range of experiences of eighteen asylum seekers and refugees from several different origin countries. This is achieved by examining the relationships between their experiences and the structure-agency 'coin'.

The use of structuration theory may also be of value to policy makers (Martin 2001). For example, the value of understanding how refugees feel in their host society is important, particularly in attempts to improve the integration of refugees after they have received formal status (Ager and Strang 2004).

\section{THE EXPERIENCES OF ASYLUM SEEKERS AND REFUgEES IN THE UK}

The media and the public have developed a growing interest in asylum seekers over recent years as the number of people seeking asylum has increased. The number of applications in the UK rose from 22,370 in 1993, to a peak of 103,100 in 2002. The following year the numbers fell back to 61,050 (National Statistics, 2003), and continued to fall to 33,960 in 2004 (Heath and Jeffries, 2005). These statistics are much publicised within parts of the media, in particular in red-top newspapers such as The Daily Mail. Such newspapers have used these statistics to create the impression that the increased numbers of asylum seekers coming to the UK are choosing to enter for economic reasons, so-called 'economic migrants', rather than coming because of persecution. They argue that these economic migrants, who are claiming to be asylum seekers, are taking 'British people’s jobs' or 'sponging off the welfare state'. This has been cited as 'The Daily Mail effect' (Bowcott, 2004). Perhaps as a result of this negative media response, the government has interpreted the fall in the numbers seeking asylum, as in 2003, to indicate that the UK is not allowing 'bogus' asylum seekers into the country. This has led to confusion between categories of migrants, by alternating the terms 'bogus' and 'illegal' migrants with 'asylum seekers' (Lynn and Lea, 2003). Koser (2001: 90) comments that restrictive asylum policies have 'only introduced further complexity by blurring the distinctions not just between economic migrants and political refugees, but now also legal and illegal migrants'. This response by different groups of people in the UK influences the agency of asylum seekers and refugees, 
as the structures in the UK imply that they are not welcome. Three aspects of the asylum seeker and refugee experience are considered here: the actual experience, the choice of the UK and the coping strategies adopted.

\section{Experience of the UK}

Despite in the past being a humanitarian host, Britain now 'reluctantly provides sanctuary for those whose security and protection from persecution are paramount' (Zetter and Pearl, 2000: 675). Koser (2001: 87) argues how 'refugees became a symbol of system overload, instead of a symbol of what was always best in the Western liberal tradition'. The experience of asylum seekers and refugees is an important area for research as experiences impact upon the integration and settlement of refugees in the UK. As Zetter and Pearl (2000: 675) argue 'since the mid-1990s, policies and legislation for refugees and asylumseekers have become increasingly restrictionist in the UK'. There has been a shift from resettlement and political asylum to temporary protection and repatriation, as the most attractive resolution to the issue of refugees (Franz, 2003). This structural policy reduces the control the asylum seekers and refugees have over their length of residence in the UK.

These policy changes have impacted upon the experiences of asylum seekers and refugees. Experience is affected by the level of integration into the host society. Al-Ali et al (2001b: 582) argue in their study that 'many refugees started to perceive their initial temporary place of residence as a long-lasting if not permanent one'. This impacted upon their experiences as they began to integrate into mainstream society. Integration may be defined as the 'contact established between migrants and host society and with the absorption of the migrant group into certain aspects of host society activities' (White, 2001: 81). The different experiences of asylum seekers and refugees impact upon the extent of integration that occurs. Positive experiences can lead to greater contact between migrants and the host community, whereas negative experiences can result in more distance being created between migrants and the host community. Increased contact with the host community increases the feelings of comfort in the host country. White (2001: 83) argues that 'integration is seen as an important issue in part because it reflects a certain fear and mistrust of difference and an inability on the part of society to countenance some of the 
implications of fragmentation and the loss of apparent unity’. Asylum seekers and refugees are encouraged to integrate into society through structural forces because their 'otherness' creates fear towards them from some sectors of the public.

\section{Choice of the UK}

It is important to recognise the impact of the asylum seekers' and refugees' choice of the destination country on their subsequent experiences. Cuny and Stein (1991) argue that asylum seekers and refugees will often only move to another country where they are reasonably certain that they will be able to exercise power and control over their own fates. The UK is perceived to be such a country, because as a democracy it is believed that people are treated as equals. Although equality is not always the case, as illustrated above, such a belief could explain the decision to choose the UK as a destination country for some asylum seekers. It seems that where they have a choice, asylum seekers and refugees choose destinations where they believe that negative experiences will be minimised.

On behalf of the Home Office, Koser (2003) has studied what asylum seekers know when they arrive in the UK. Through interviews with 87 asylum seekers of both sexes, from a range of ages, and from a number of origins including Afghanistan, Somalia and Colombia, he suggests that there is not always a 'choice' involved in the arrival of asylum seekers in the UK. In general Koser found that it was the people who were trafficking the asylum seekers who decided their destination (Koser, 2000). Morrison and Crosland (2001) go as far as to argue that addressing trafficking and smuggling in an aggressive manner could be the 'end game' in European asylum policy, in that trafficking is one of the few means by which people seeking asylum can travel to a country they perceive to be safe. Koser's study finds that where traffickers give asylum seekers a choice, the most important factor in the decision-making process is whether they have family or friends who already live in one of the countries on offer (Brooks, 2003). The next most important factor is whether the asylum seeker can speak the language of the country they are considering; and thirdly there is the cultural affinity between the country of origin and the country of destination - the 'cultural legacy of empire' (p2). Upon arrival in the UK, the previous 
experiences of asylum seekers and refugees differ, as do the coping strategies they adopt to deal with the transition into a new society.

\section{Coping Strategies}

Coping strategies are attempts by asylum seekers and refugees in the host country to regain agency in their 'new' society. In her study of the lives of Hmong women in Syracuse, USA, Monzel (1993) talks about coping strategies used by women to deal with their experiences. She notes how one of her interviewees, Kue, remarked on how she 'lived only one day at a time' (p16) and how many of the people around her smoked opium as a way of remaining calm. Coping strategies are adopted wherever asylum seekers and refugees are situated. Another way that people cope is through attempts to adjust to their new circumstances. Ward (no date: 13) comments on how Jamshed, from Afghanistan, coped with his new life in the UK through learning to speak English well, and taking a computer course at a local college: 'he hopes eventually to be able to continue his studies to be a doctor.' When their feelings of comfort in the host country are low, various strategies are used by asylum seekers and refugees to allow them to cope, such as taking drugs, being proactive in education, or by adopting a positive outlook that things will change for the better.

There is a distinction to be made between externalised and internalised coping strategies. Externalised coping strategies consist of ways of dealing with the situations asylum seekers and refugees face, and involve them taking external actions involving other people. Internalised coping strategies are achieved through internal beliefs that are inherent to the individual, they are ways of thinking about and seeing the world. Internalised coping strategies are largely connected with ontological security (a person's understanding and acceptance of their own place within their worldview). Such strategies contribute to the perception of where people see themselves within their worldviews. For example, asylum seekers might accept differences in social structure and develop positive attitudes towards change in order to make themselves feel more part of the host society: for instance an unemployed refugee might become involved in volunteering (Volunteering and Asylum Project, 2004). Externalised coping strategies are often linked to internalised coping 
strategies, in that it is the attitudes of people that make them seek to regain an external sense of security in the host country.

\section{CONCEPTUAL FRAMEWORK: STRUCTURATION THEORY}

Structuration theory highlights how experiences are constrained by structures. Bloch's (2000: 75) work illustrates that structural forces, for example the immigration status (i.e. 'asylum seeker', 'refugee') applied to an individual, have a marked impact on the experiences of people in the host country. Here Bloch's ideas are developed further, by examining a group of people who have limitations put upon their human agency, due to their relatively low levels of self-determination. The relative importance of 'structure' and 'agency’ varies, as structural forces are a part of every action of human agency. Asylum seekers and refugees respond in different ways to the opportunities and constraints available to them within the structures that they face.

\section{Structuration Theory: Asylum Seekers and Refugees}

Structuration theory, developed by Anthony Giddens (1984: 2), seeks to examine how 'the basic domain of study of the social sciences... is neither the experience of the individual actor, nor the existence of any form of societal totality, but social practices ordered across space and time.' The theory looks at the interactions between the structure of society and the agency of the humans within that social structure. Human agency is defined as 'the ability to act' (Valentine, 2001: 349). Structural forces are complex to define; they relate to the hegemonic discourses and culture of a society. These dominant ways of seeing the world are affected by the culture of that society. They influence the behaviour of individuals, through creating explicit rules and laws as to how people should act and behave, and implicit understandings of how different types of behaviour will be accepted within that society. The variations in structural forces between and within different societies, and the implicit knowledge of social structures, are particularly difficult for newcomers to a society to comprehend, especially when coming from a different cultural background. 
The structure of society affects the ways in which social processes function. For example, structural forces may influence the behaviour of asylum seekers and refugees through the discourses of colonialism and patriarchy. Central to social theory is the dualism between 'agency' and 'structure'. Giddens believes that previous work was mistaken in bringing together the two terms: authors treated 'structure' as creating the parameters within which 'agency' was able to practice. Instead Giddens views structure as being implicated in each moment of action. Structure is at the same time both constraining and enabling. However, conversely, structure is also an 'absent' discourse, 'present' only in moments of interaction through which it is reproduced or changed (Gregory, 2000b).

Human agents are complex and more powerful than organisms simply responding to stimuli (structural forces) (Giddens, 1984). Schutz (1972) argues that they have 'stocks of knowledge'. These are formed from the constant monitoring of the flow of their activities, and agents also expect others to be undertaking similar monitoring. Through these 'stocks of knowledge', human agents can rationalise their actions. No action is made in suspension from the rest of the person's life (Gutting, 1996). Agency is equated with power, as the human agent always has the possibility to act otherwise (Giddens, 1984). Agency applies to subjects; there is never a purely individual action, as there are always socio-cultural, psychological and material factors involved in the conditions and consequences of action.

As individuals grow up in society, the systems and structures come before individual agency. This process of socialisation means that individuals incorporate structural influences at the same time as being surrounded by both structural constraints and facilities. Therefore structure has an important role in explaining events. However, structures do not have independent existences, they continue only to the extent that individuals reconstruct them through their experiences of the social system and the reproduction of the structures through individual actions (Sarre, 1986). This is known as the 'duality of structure' in that structures are implicated in every action of individuals and yet are produced by individuals.

The connection between 'agency' and 'structure' is dependent upon three concepts: reflexivity, recursiveness and regionalization. Reflexivity refers to the concept that the production and reproduction of social life is an achievement by informed actors instead of a 
spontaneous response to structural forces (Giddens, 1984). It emphasises how things change within the structural components of society through human agency. For example, in some communities in Britain individual agency can reproduce patriarchy at a household level: this exemplifies the duality of structure (e.g. Mohanty 1991; Halfacree 1995). Recursiveness is where social life occurs under conditions that are not completely comprehended or planned by the social actors, for example the feelings of exclusion felt by some asylum seekers due to the response from the host community. Regionalization refers to how social life continues through the interactions between people who are co-present in space and depends on relations that reach beyond the present moment to enable intergenerational exchanges (Giddens, 1984). For example, regionalization could involve the maintenance of contact between individuals living in different parts of the world, living in similar ways such as social transnationalism (Al-Ali et al., 2001b); or the continuance of structural forces between generations. Reflexivity is the dominant concept of structuration theory used within this study.

\section{Reflexivity: Ontological Security, Practical and Discursive Consciousness}

The concept of reflexivity, in the context of this study, focuses on the relationship between agency and structure, and the ways in which this relationship impacts upon the lives of asylum seekers. Reflexivity illustrates the experience of asylum seekers and refugees in the UK. The concept that social life is reproduced through the knowledge of human beings rather than a mechanical response to an overarching structural force, consists of three elements: ontological security, practical consciousness, and discursive consciousness (Giddens, 1984).

Ontological security is a person's understanding of their place within their worldview and with which they feel comfortable. Forced movement to another country disturbs this; therefore asylum seekers lose relative stability in their known world, through the amount of agency that they can exert. In the new society, they have to re-establish a level of ontological security through gaining an understanding of the structural forces that they are working within, and the levels of agency they can exert within these structural forces. The balance between structure and agency within migrant groups is different from 
that of residents. This situation creates certain experiences that impact upon the way the asylum seekers and refugees integrate into the host society.

Practical consciousness exists when people unconsciously monitor the events occurring around them (Giddens, 1984). Practical consciousness is the unconscious recognition of the events and structures that surround them: the taken-for-granted nature of the structural systems that they are in. The nature of practical consciousness means that, unlike their discursive consciousness views (see below), individuals will not report their practical conscious views: hence analysis of interview data requires reading between the lines of what they are saying. How people behave says something about the forces that are impacting upon them. An example of this is colonialism. The thought patterns of some asylum seekers and refugees are based within their taken-for-granted post-colonialist worlds. Colonialism is part of the practical consciousness of these asylum seekers and refugees. The practical consciousness indicates the long-term structures that are in place in their origin societies. Practical consciousness acts at a more structural level than discursive consciousness (Giddens, 1984). For example, the experience of living in the UK may be a more positive experience for asylum seekers and refugees who had colonial connections prior to arrival, because they have a greater understanding of, and feelings of comfort with, the cultural practices in the UK.

Discursive consciousness involves people being able to give a coherent account of their activities and reasons for them (Giddens, 1984). This consciousness is what they are able to talk about in their understanding of the world around them. An example of discursive consciousness is the respondents' narration of the experiences that they have had in the UK. Discursive consciousness tends to operate more within an individual's agency. Figure 1 is a heuristic device to convey the relative positions of practical and discursive consciousness in relation to structure and agency within the concept of reflexivity.

\section{*FIGURE 1 about here*}

Structuration theory has not often been explicitly used in empirical studies. As Gregson (1989) argues, 'it is hardly a surprise that there should have been so few empirical exemplifications of structuration theory inside or outside human geography,' because even Giddens supported methodological practices that examined the human agents or the 
societal structures. However, aspects of structuration theory are frequently imbued into much research although not distinguished as such (e.g. Al-Ali et al 2001a). This study attempts to apply some of the concepts drawn from this theory rather than attempting a full exemplification, using empirical research based on interviews drawing on the respondents' comments to examine societal structures.

\section{RESEARCH EVIDENCE}

Interviews were carried out with eight male and ten female asylum seekers and refugees in two medium sized cities. Twelve refugees and six asylum seekers were interviewed. This is a higher number than interviewed by some other published studies such as that by Monzel (1993), who interviewed three women. The asylum seekers and refugees came from a range of countries, including, Poland, Somalia, Kenya, Eritrea, and the Yemen. The inclusion of interviewees from the Yemen and Kenya enables the colonial connections of structural forces influencing experiences of the UK to be examined. The interviews were mainly carried out in English; however where necessary interpreters were used. These were generally friends of the participants. Interviews were also carried out with some of the volunteers who worked at the refugee centres. Pseudonyms have been used throughout the in order to preserve the anonymity of the respondents.

Two contrasting cities were chosen in order to increase the range of asylum seekers and refugees interviewed. This supported an aim of achieving a range of experience rather than being representative. City A has a population of around 100,000 people whereas City B has a population of just over 500,000. Both cities have a similar proportion of asylum seekers at around $0.3 \%$ of the population.

The use of structuration theory to analyse these findings unites the agency-structure dimension of the experiences of asylum seekers and refugees. The heuristic device of Figure 1 is used to illustrate visually where practical and discursive consciousness are positioned in relation to agency and structural factors. However, the reality of the relationship between agency and structure is more complex than is implied by this heuristic. People's experiences are complicated and influenced by their own agency as well as by the 
structures of the society in which they are living and those of their country of origin. In order to interpret these experiences it is possible to make distinctions between the discursive and practical consciousness involved in individual experiences.

\section{Experiences of asylum seekers and refugees in the UK}

The experiences of asylum seekers and refugees can be looked at through their discursive consciousness by examining the different strengths of agency and of structural factors within those experiences. The feelings of the asylum seekers and refugees about their situation are approached through an interpretation of the practical consciousness of the respondents. This was identified by examining the way participants felt about the experiences they had had in the host country.

Discursive consciousness

Discursive consciousness examples are grouped into two sections: agency and structure. Whilst this facilitates in-depth analysis, it is important to recognise that agency and structure are not dualistic categories. The following experiences illustrate those where participants identified their own power (agency) within the situation as opposed to the dominance of societal structures. Four factors, place, language, people and childcare are used to illustrate respondents' discursive consciousness and experiences where agency was more significant than structural forces.

There were a variety of experiences of place, both negative and positive. Brian talked of the things he would like to do once he received his asylum decision.

Well if I receive refugee status, for a month I will travel and see friends. I have travelled so many places. I have been to Devon twice... Cornwall, Manchester, Birmingham, and London many times, and I've been to Wales. It is a very nice place apart from the weather, which is terrible, it has nice sceneries... it is a very nice place here, and a nice experience.

Whereas Brian's experience of the UK was one of pleasure and enjoyment, Enya from Poland, had experienced a more negative view of the UK when she first arrived and lived in Folkestone. However, since arriving in City A she has been much happier, 'here [City A] there is more ... in Folkestone - it was more just English, just white. We don't have a problem here, because here it is more mixed.' Enya's experience in the UK has been 
varied; she first dealt with segregation as she and her family stood out within one area, and then experienced greater integration when dispersed to another.

Language may be both a structural and agency factor in experiences in the destination country. Learning a language for a purpose demonstrates the agency of an individual, whereas learning a language 'just because' it is what is expected of a migrant, indicates action in response to structural forces. Language is a complex feature of the experiences and coping strategies of asylum seekers and refugees. It is a practical skill yet also a vehicle of expression and a structural means of understanding. Language is both an agency and structural force as the means between which individuals and society communicate.

Language was a common individual experience for the participants in which they had agency over becoming more competent with the language. Meriton's interpreter said that she found 'British people...very kind...but she has no contact because of language.' Making contact with local people is difficult when the asylum seeker or refugee does not speak English. Abdi also found language problems to be an issue, although in a different way from Meriton. He found that in his house 'there is also a language barrier.' This was because of the different backgrounds of the people who are put together in asylum seeker accommodation, making interactions between people difficult.

Local residents in the host communities affected the experiences of asylum seekers and refugees. The majority of interviewees talked of how people had been good to them; for example Biana commented how ‘they are very kind.’ However, some people had negative encounters with British people; for example Abdi remembered when he first arrived:

once when I was in Dover... this guy comes, a huge guy yes... he said 'hey you, you shouldn't be here, we don't want you here... you should be very careful wherever you walk'.

Although this attitude was a rare experience in which Abdi defused the situation by explaining the reality of being an asylum seeker, discrimination can occur. In this case Abdi took control of the situation, impacting on how the experience developed. Dominant structures create discourses which encourage anti-asylum rhetoric in the local population. 
Childcare was an important experience, particularly for women. Enya commented how her experience as a job seeker has been difficult because

I have small children... [I bring them to] the playschool, but for the smallest one, because he has a heart problem... they tell me they need to check his health and monitor his blood. It is nearly every week I need to go to the hospital.

Sadia also commented how 'childcare is really a nightmare here because you can't work, you can't study, because you don't get...childcare.' The lack of an extended family in the UK emphasises how childcare is a feminised experience. Due to patriarchy for some of the interviewees at the familial level, the responsibility for the children was found to lie solely with the women. However, individual women could use their agency to dispute this structural force and alter the way children are cared for in Britain. The patriarchal structure was more explicit before they were refugees, yet more difficult to challenge as more greatly implicated in people's actions in their origin societies.

Language, cultural differences, and tabloid newspapers are the three examples used to illustrate the discursive consciousness experiences in which structural forces had dominance.

Structural forces enhance the importance of learning English. Problems with the English language were common general experiences for asylum seekers and refugees in the UK. Nissa summed up the problem, 'firstly there are language difficulties, which leads to the second problem of difficulty finding a job, and thirdly social life problems.' Language problems affect other parts of the lives of asylum seekers and refugees, as they limit employment and social interaction. Emma, a volunteer in City A, pointed out an example of complications caused by language difficulties.

Language is a huge issue - in an incident a few weeks ago, a woman applied for a nursing course thinking that she had signed up for one year - only to discover that in fact it was two years - quite a big difference! Because the understanding of our academic system is so different, and language understanding limited, it is so hard for people to always know what they are getting involved in. Language and education are structural factors which the respondents have little agency to control.

Cultural differences were frequently cited as general experiences that people noticed. Nissa pointed out the economic implications of some of the differences. 
The difference in the cultures of countries is a problem for them. I am from Africa with a socialist government - so even if you are poor you are helped, but here in this capitalist country, you can be poor and have nothing. It is a very hard life for people in this country.

For those coming from a socialist society, the experiences of some of the asylum seekers and refugees once in the UK could be quite contrary to their previous understandings. Brian also added how women are treated differently in the UK, 'it is so different here, seeing a woman smoking in my country is practically unheard of, it would be assumed she was a prostitute.' The difference in cultures makes integration into UK society more difficult.

Although only explicitly mentioned by Adil, the media, in particular the red-top press, probably impacted upon other asylum seekers and refugees in the study, as the media influences public perceptions of asylum seekers and refugees. Adil mentioned some of the anti-asylum seeker headlines:

'The country has been invaded by aliens',...just inflating something that is not worth mentioning, something trivial but inflating it very high, just like flaming words like 'bogus' and 'racketeer'. Such headlines fuel negative attitudes from British nationals towards asylum seekers and refugees.

Discursive consciousness is a useful tool as it shows the specific areas of the experiences which participants identified as being particularly influential. However practical consciousness illustrates the information that the participants did not voice specifically, indicating at a deeper psychological level the amount of agency they felt within the structures of the host country.

\section{Practical consciousness}

This section examines the feelings of the asylum seekers and refugees through their practical consciousness. Within structuration theory practical consciousness has a larger role than discursive consciousness, as Giddens (1984) emphasises how individuals are influenced by structural factors without consciously recognising them.

Although it was rare for interviewees to say directly how they were feeling, an indication of this could be gained through reading between the lines of what they said. The concept of recursiveness may be illustrated by the feelings of some of the asylum seekers and refugees. For example, the public reaction towards asylum seekers and refugees, 
created by the anti-asylum rhetoric, may make an asylum seeker or refugee feel uncomfortable as they have little or no control over these views. The negative feelings reported in some of these interviews involved distress and loneliness. However, there were also cases of people who were content with their current situations. In terms of her immediate arrival in the UK, Natalya commented how

I find questions distressing, I don't like them... since I've been here everyone keeps asking me questions, and people don't trust me - it is hard when people do not believe what you tell them. The interviews that asylum seekers go through at the beginning of the application process can be distressing and make them uncomfortable about other interviews, such as those required for this research. Loneliness also impacted upon people's lives in the UK. Mulgeta from Eritrea spoke directly about his feelings

Loneliness... yes, it is difficult when not working, then it is difficult working and mixing study, [but it is] hard to live, when far away [from home], when you come far away from countries it is quite difficult.

Despite these negative feelings associated with first arriving in the UK, some asylum seekers and refugees had adapted to their new lives and were content in the UK. Alfi commented how he was ‘enjoying being part of this [UK] society' and how 'I volunteer to serve people here, and I feel I have a stable relationship with the society and the integration part of society, I feel at ease.' Minuet, from the Yemen, also described her contented state and how the people 'have been very good, very cute and nice!' Having had time to settle into the UK, these examples illustrate contentment as the individuals have reestablished a level of ontological security.

Examples of routine and habits also illustrate the practical consciousness of the individuals interviewed. For Abdi, the refugee centre was part of a routine, as it acted as a place for him to go, 'I usually come much to this place, it is useful for me.' Although he may not think of it as a specific experience in the UK, his practical consciousness leads him to visit the refugee centre routinely.

To summarise, an examination of the practical consciousness provided a deeper analysis of the way asylum seekers and refugees felt and responded to their situations, depending upon their perceived level of agency in the host country. 


\section{Coping strategies}

Internalised and externalised coping strategies illustrate the practical and discursive consciousness of asylum seekers and refugees. Coping strategies are a way in which asylum seekers and refugees can re-establish ontological security in the host country. All the coping strategies identified here were adopted in order to deal with structural factors.

Internalised coping strategies are closely related to practical consciousness as individuals did not initially comment that they were coping strategies. However, when an interviewee discusses these internal coping strategies they then become part of the discursive consciousness. Internalised strategies can be seen as methods of adjusting to new ways of thinking and seeing the world, in order to deal with the situations in which the respondents find themselves.

The main internalised coping strategies used by the interviewees relate to their attitudes or religious beliefs. As these internalised methods are part of their practical consciousness, they are used frequently by the respondents but without being recognised by them. People's attitudes enable them to cope with situations in different ways. Faisali's attitude is one of keeping his distance, 'I have some friends here, they go out sometimes, usually I don’t go because I don’t want to get too attached, I might feel something for them.' His attitude towards fear of intimacy protects him against the possibility of rejection. In contrast, Adil is proactive in his approach to coping.

Well personally I am born to fight... I am born to fight... I struggle everything.. I never doubt... that is my principle! I will try everything and I will keep on trying until I succeed, that is my motto. So if one way is blocked I go the other way...

This fighting spirit is Adil's proactive way of coping with things that are hard for him.

The asylum seekers and refugees interviewed came from various religious backgrounds and many, on the level of practical consciousness, used their religion as an internalised method for coping with their circumstances. Abdi, a Christian, did so:

You fear integrating because you don't know who really wants you and who doesn't want you. So I go to the church; they had a course where you could meet people.

Abdi found his religion a comfort when he did not feel that he fitted in anywhere. This is also an example of regionalization where structural forces in Abdi’s life continue through 
interactions between people. Mulgeta, as an Orthodox Christian, with no church in the area, had to find a different way of performing his religious duties, 'there is no Orthodox, but it is just I am going to Catholic Church, and I read the Bible at home.'

Internalised coping strategies show how participants regained a higher level of ontological security through their attitudes or religious beliefs. Through these ways of thinking or seeing the world, participants adjusted to the different structural parameters in place in the host country.

These examples illustrate the relationship between internal and external coping strategies. Internal strategies provide the internal belief system or motivation to conduct external coping strategies. This research found two main externalised coping strategies. These involve seeking firstly education, and secondly help from others. Externalised coping strategies express discursive consciousness as there is a clear deployment of agency. However, practical consciousness underlies these actions as they are impacted by internal strategies of coping.

As language difficulties were a common experience, many interviewees stated how one of their coping strategies was to go to language classes. Rosa's interpreter commented how 'she is going to English classes every week at this centre [City B] to try to get over the problem, and improve her English so that it is easier for her to speak to people.' In terms of feeling accepted in their new environment, language is crucial to 'fitting in', so people try to learn English so that they can communicate with the local population. This external deployment of agency is in response to respondents' understandings of the host country from the standpoint of both practical and discursive consciousness. Within the realm of education some of the interviewees found that studying was also a way of keeping motivated. Again, the incentive may be from practical consciousness, but discursively acted upon in the form of education. For example, Faisali, from Algeria, commented how he was 'doing a computer course, I done forklift licence already.' Many of the people interviewed were either studying or wanted to study, because structural factors influenced their practical consciousness and encouraged education as a way of improving their chances of succeeding in the UK. In discursively choosing to partake in education for such reasons asylum seekers and refugees can increase their level of ontological security. 
Some of the people interviewed were willing to accept help from others, either from family or friends, or from organisations such as social services, or the local refugee centre. The refugee centres assisted the interviewees in various ways, for example for Meriton 'they helped fill in immigration papers and immigration problems.' Rosa found in City B that 'NASS [National Asylum Support Service] has helped her a lot.' Other interviewees found support from friends as a way of dealing with their situations. Sadia and her husband had become good friends with one of the refugee centre volunteers.

Angela was our best friend, she is our best friend, she has helped a lot, yes, when we came to this country we met at the refugee centre and she was really nice.

Externalised coping strategies indicate the actions participants took in order to re-establish a higher level of agency through their different coping strategies.

The asylum seekers and refugees in this study found that the main factors they needed coping strategies to deal with were structural. These could be addressed at the level of the national and local government in order to enable asylum seekers and refugees to adjust their coping strategies to manage issues where they have more self determination.

\section{SUMMARY AND CONCLUSION}

This research has explored a theoretical way of explaining the experiences of asylum seekers and refugees in the UK. Structuration theory allows the combination of structure and agency in the experiences of asylum seekers and refugees to be analysed through the concepts of discursive and practical consciousness and through the level of ontological security of the interviewees. Through an analysis of the coping strategies used, structuration theory indicates where a loss of agency has occurred and the attempts to reestablish it. Asylum seekers and refugees are groups in society with the least human agency, particularly when they arrive in their destination country with few or no legal rights. They are often a marginalized and powerless group whose personal experiences are rarely heard. Given that relatively few previous studies of the experiences of asylum seekers and refugees have used the same analytical tools as those utilised here, an exploratory study was chosen. 
The main findings of the study are summarised in Figures 2 and 3. Figure 2 illustrates how the experiences of the asylum seekers and refugees are related to their feelings and their level of ontological security. Figure 3 suggests how the coping strategies adopted enabled an increase in ontological security. These diagrams are used as heuristic devices to simplify what are complex relationships. For example, as people are shown on a continuum, a direct play off between structure and agency is implied. However, individuals from the same community can face similar structural forces, yet the amount of agency they have can vary. This may be, for example, due to their characters, which enable them to find different opportunities within the same structure. Structuration theory assists in breaking down this dualism between agency and structure.

*FIGURE 2 and FIGURE 3 about here*

Of key importance in these findings is the recognition of the impact practical consciousness has in respect to the experiences of asylum seekers and refugees. Practical consciousness is most closely related to the feelings of the individuals involved and the structures which are impacting upon them.

The main element of experience that emerges in this research, and which connects to previous literature, relates to language. This is a structural factor which impacts upon the experience of asylum seekers and refugees. Many of the asylum seekers and refugees who came to the UK had to learn English. This was presented as a challenge and something that they had to do in order to integrate into British society. However, there was variation as to whether individuals were learning English for a purpose, discursively and with agency, or as part of a routine, through their practical consciousness and in response to societal structures.

The use of ideas from structuration theory has shed light on the experiences of asylum seekers and refugees. However the theory has limitations. For example, two criticisms are relevant to this study. Firstly, Giddens is seen by some as having a 'weak understanding of culture' (Gregory, 2000b: 800). It is generally accepted that culture is 'an active force, working through people and possessing existence or agency beyond its specific and contingent historical and geographical expressions' (Cosgrove, 2000: 143). As structuration theory does not automatically cater for culture, greater weight has been given 
to cultural variations in influencing the behaviour of asylum seekers and refugees in this article. Secondly, structuration theory emphasises the idea of 'rational action' by the human agent (Gregory, 2000b). This leaves little space for the passions and desires of many asylum seekers and refugees, as reflected in the fears and emotions involved in their flight from their countries of origin and the uncertainties involved in the asylum process. This weakness of structuration theory is more difficult to overcome as rational action is more fundamental to the relationship between agency and structure as defined by the theory.

With these concessions in mind, useful findings can still be acknowledged. The specific experiences of asylum seekers and refugees vary from individual to individual, but there are, however, major structural similarities between them. The nature of the coping strategies suggest that structural factors have a major impact upon their experiences. These findings are important because they impact upon the Home Office (2004) proposals in Integration Matters in that they indicate the numerous barriers to integration into the UK. They contradict some of the suggestions made by the Home Office. They suggest that as structural forces have a stronger impact on their experiences than factors which individual agency could address, then the longer the asylum seeker or refugee is in the UK without proper support, the more difficult these barriers will be to overcome.

The question remains as to how to improve or maintain a reasonable quality of life experience for asylum seekers and refugees who are already in the UK or who may come here in the future. Structural factors affecting the asylum seeker and refugee experience limit the integration when they become refugees. Asylum seekers and refugees need to be treated in a more constructive way, with government policy seeking to allow asylum seekers and refugees to achieve their full potential, rather than view them as a 'problem issue'. Adil sums up the potential of refugees in the UK:

For those people who are educated, like me, it will be easier... when you compare it to those of poor educational background, poor experiences... but the problem is still there. What I think is governments should be able to promote some healthy relationship among the members of the public and the asylum community... just to help integration. I think we can contribute a lot to this economy and culture, lots of things! 


\section{ACKNOWLEDGEMENTS}

I wish to thank those asylum seekers and refugees who agreed to be interviewed, and the staff and volunteers at the two refugee centres for their help. I would also like to gratefully acknowledge the contributions of my supervisor Paul White for his continued advice and support; Lucy Crane for her insightful comments; and the two anonymous referees for their suggestions. An earlier version of this paper was presented at the Association of American Geographers’2005 Annual Conference in Denver. 


\section{REFERENCES}

Ager A, Strang A. 2004. The Experience of Integration: A Qualitative Study of Refugee Integration in the Local Communities of Pollokshaws and Islington. Home Office: London.

Al-Ali N, Black R, Koser K. 2001a. Refugees and transnationalism: the experience of Bosnians and Eritreans in Europe. Journal of Ethnic and Migration Studies 27(4): 615-634.

Al-Ali N, Black R, Koser K. 2001b. The limits to ‘transnationalism’: Bosnian and Eritrean refugees in Europe as emerging transnational communities. Ethnic and Racial Studies 24(4): 578-600.

Bloch A. 2000. Refugee settlement in Britain: the impact of policy on participation. Journal of Ethnic and Migration Studies 26(1): 75-88.

Bowcott O. 2004. Is this the Daily Mail effect? Why Blair will look again at the 'risk' of influx from Europe. Available at http://www.obv.org.uk/reports/2004/rpt20040205e.htm, accessed 04.09.2004.

Brooks L. 2003. Asylum: a special investigation: 5 tough questions about asylum: Britain goes to the polls today, at the end of a local election campaign that has been dominated in many areas by asylum. The Guardian. $1^{\text {st }}$ May: 2 .

Cosgrove D. 2000. Culture. In The Dictionary of Human Geography, Johnston RJ, Gregory D, Pratt G, Watts M (eds.); $4^{\text {th }}$ Edition, Blackwell: Oxford: 143-146.

Cuny FC, Stein BN. 1991. Introduction. In Repatriation under Conflict in Central America, Larkin MA, Cuny FC, Stein BN (eds.); CIPRA \& Intertect: Washington DC: $1-8$.

Findlay A. 2004. Population geographies for the $21^{\text {st }}$ Century. Scottish Geography Journal. 119(3): 177-190.

Franz B. 2003. Bosnian refugees and socio-economic realities: changes in refugee and settlement policies in Austrian and the United States. Journal of Ethnic and Migration Studies 29: 5-25.

Giddens A. 1984. The Constitution of Society: An Outline of the Theory of Structuration. Blackwell: Oxford. 
Goss J, Lindquist B. 1995. Conceptualizing International Labour Migration: A Structuration Perspective. International Migration Review 29(2): 317-351.

Graham E. 2000. What kind of theory for what kind of population geography? International Journal of Population Geography 6: 257-272.

Gregory D. 2000a. Human agency. In The Dictionary of Human Geography, Johnston RJ,

Gregory D, Pratt G, Watts M (eds.); $4^{\text {th }}$ Edition, Blackwell: Oxford: 349-352.

Gregory D. 2000b. Structuration. In The Dictionary of Human Geography, Johnston RJ, Gregory D, Pratt G, Watts M (eds.); $4^{\text {th }}$ Edition, Blackwell: Oxford: 798-801. Gregson N. 1989. On the (ir)relevance of structuration theory to empirical research. In Social theory of modern societies: Anthony Giddens and his critics, Held D, Thompson JB (eds.); Cambridge University of Press: Cambridge: 235-248. Gutting D. 1996. Residential Histories of Munich’s Turkish Population: A biographical approach to urban residential mobility. Unpublished $\mathrm{PhD}$ Thesis. University of Sheffield.

Halfacree K, Boyle P. 1993. The challenge facing migration research: the case for a biographical approach. Progress in Human Geography 17(3): 333-348.

Halfacree K. 1995. Household migration and structuration of patriarchy: evidence from the USA. Progress in Human Geography 19: 159-182.

Heath T, Jefferies, R. 2005. Asylum statistics United Kingdom 2004. Available at http://www.homeoffice.gov.uk/rds/pdfs05/hosb1305.pdf.

Home Office. 2004. Integration Matters: A National Strategy for Refugee Integration. Available at http://www.ind.homeoffice.gov.uk/ind/en/home/laws__policy/consultation_docum ents/current_consultations.Maincontent.0002.file.tmp/COI_NATI.pdf, accessed 04.09.2004.

Koser K. 2000. Asylum policies, trafficking and vulnerability. International Migration Special Issue: 91-111.

Koser K. 2001. New approaches to asylum? International Migration 39(6): 85-101.

Koser K. 2003. What do asylum seekers know when they arrive in the UK? Guest lecture, University of Sheffield, $18^{\text {th }}$ February. 
Lynn N, Lea S. 2003. A phantom menace and the new apartheid: the social construction of asylum seekers in the UK. Discourse \& Society 14(4): 425-452.

Martin R. 2001. Geography and public policy: the case of the missing agenda. Progress in Human Geography 25(2): 189-210.

Mohanty CT. 1991. Under western eyes: feminist scholarship and colonial discourses. In Third World Women and the Politics of Feminism, Mohanty CT, Russo A, Torres L. (eds.); Indiana University Press: Bloomington: 51-80.

Monzel K. 1993. “Only the women know”: powerlessness and marginality in three Hmong women's lives. In Geography and Refugees: Patterns and Processes of Change, Black R, Robinson V. (eds.); John Wiley, London: 118-133.

Morrison J, Crosland B. 2001. The trafficking and smuggling of refugees: the end game in European asylum policy? Working Paper No.39. Available at http://www.unhcr.ch/cgi-bin/texis/vtx/home?page=search, accessed 04.09.2004.

National Statistics. 2003. Asylum applications: by region of origin 1991-2000. Social Trends 32. Available at http://www.statistics.gov.uk/StatBase/ssdataset.asp?vlnk=4962\&Pos=2\&ColRank= $1 \&$ Rank=272, accessed 04.09.04.

Richmond AH. 1993. Reactive migration: sociological perspective on refugee movements. Journal of Refugee Studies 6(1): 7-24.

Sarre P. 1986. Choice and constraint in ethnic minority housing: a structurationist view. Housing Studies 1: 71-86.

Schutz A. 1972. The Phenomenology of the Social World, Heinmann Education Books: London.

Silvey R. 2004. On the boundaries of a subfield: social theory’s incorporation into population geography. Population, Space and Place 10: 303-308.

Valentine G. 2001. Social Geographies: Space and Society. Prentice Hall: London.

Volunteering and Asylum Project. 2004. Promoting volunteering by asylum seekers and refugees in mainstream organisations. Available at http://www.localfoodworks.org/web/sa/saweb.nsf/0/9d0e251f7d0fb4fb80256fle004 4dc6e?OpenDocument, accessed 16.10.2004. 
Wahlbeck Ö. 2002. The concept of diaspora as an analytical tool in the study of refugee communities. Journal of Ethnic and Migration Studies 28(2): 221-238.

Ward D. no date. Seeking safety: refugees in Britain today. Refugee Access: 12-13.

White P. 2001. Refugee and immigrant integration. In Bridging the Information Gaps: A Conference of Research on Asylum and Immigration in the UK, London, Home Office: 80-86.

White P, Jackson P. 1995. (Re)theorising population geography. International Journal of Population Geography 1: 111-123.

Zetter R, Pearl M. 2000. The minority within the minority: refugee community-based organisations in the UK and the impact of restrictionism on asylum seekers. Journal of Ethnic and Migration Studies 26: 675-697. 